\title{
La contracultura beat: un puente entre la música negra y el rock ${ }^{i}$ \\ The beat counterculture: a bridge between black music and rock \\ A contracultura da batida: uma ponte entre a música negra e o rock
}

\author{
Alfredo Stornaiolo Pimentel ${ }^{1}$ \\ Universidad de Los Hemisferios (Ecuador) \\ astornaiolo@gmail.com
}

Fecha de recepción: 15 de julio de 2019

Fecha de recepción evaluador: 16 de agosto de 2019

Fecha de recepción corrección: 16 de septiembre de 2019

\begin{abstract}
Resumen
La milenaria cultura africana y las ilógicas formas sociales de la contracultura beat le confirieron un marco de autenticidad, identidad y rebeldía a la mayor expresión de música popular del siglo pasado: el rock. La cultura africana había llegado a América en los mismos barcos de esclavos, en forma de espíritus divinos que dieron a luz a los blues a fines del siglo diecinueve en el sur de los Estados Unidos. Un par de décadas después de los blues aparecía el jazz como una magnífica expresión cultural aceptada por todos, y a mediados del siglo veinte el rock and roll. La generación beat de Kerouac, Ginsberg y Burroughs influyó también en el movimiento contracultural de la época. La cultura (¿contracultura?) beat fue un puente entre la música negra y el rock and roll. Estos
\end{abstract}

\footnotetext{
${ }^{1}$ Alfredo Stornaiolo Pimentel: Doctor en Economía del Desarrollo por FLACSO y profesor de economía en la Universidad de los Hemisferios. Clave ORCID: 0000-0002-1058-8114
} 
rebeldes poetas amaban el jazz y escribían contra el establishment. Hay vínculos entre esta contracultura cincuentera y la música rock en la rebeldía juvenil de los sesenta.

Palabras clave: contracultura, rebeldía, autenticidad, rock, beat.

\begin{abstract}
The millenary African culture and the illogical social forms of the beat counterculture gave a framework of authenticity, identity and rebellion to the greatest expression of popular music of the last century: rock music. The African culture had arrived in America in the slave ships, in the form of divine spirits that gave birth to the blues music at the end of the nineteenth century in the southern United States. A couple of decades after blues music, jazz appeared as a magnificent cultural expression accepted by all, and in the midtwentieth century appeared rock and roll. The Beat Generation of Kerouac, Ginsberg and Burroughs also influenced the countercultural movement of the time. The Beat culture (counterculture?) was a bridge between black music and rock and roll. These rebellious poets loved jazz and wrote against the establishment. There are links between this fifties counterculture and rock music in the youthful rebellion of the sixties.
\end{abstract}

Keywords: counterculture, rebelliousness, authenticity, rock, beat.

\title{
Resumo
}

A cultura africana milenar e as formas sociais ilógicas da contracultura beat deram um quadro de autenticidade, identidade e rebelião à maior expressão da música popular do século passado: a música rock. A cultura africana havia chegado à América nos navios negreiros, na forma de espíritos divinos que deram origem à música blues no final do século XIX, no sul dos Estados Unidos. Algumas décadas após a música blues, o jazz apareceu como uma magnífica expressão cultural aceita por todos, e em meados do século XX apareceu o rock and roll. A geração beat de Kerouac, Ginsberg e Burroughs também influenciou o movimento contracultural da época. A cultura Beat (contracultura?) Era uma ponte entre a música negra e o rock and roll. Esses poetas rebeldes amavam o jazz e escreviam contra o establishment. Há ligações entre a contracultura dos anos cinquenta e a música rock na rebelião juvenil dos anos sessenta.

Palavras-chave: contracultura, rebeldia, autenticidade, rock, batida.

\section{Introducción}

A mediados del siglo veinte emergió en los Estados Unidos una manifestación cultural extraordinaria y magnífica que se convertiría en el motor de la protesta social, del cambio cultural y de una colosal industria musical. Esta revolución social, cultural y económica se conoce como rock and roll. Esta música nueva nació de la milenaria cultura africana y de un estado de inconformidad social perfectamente descrito por los poetas contraculturales de la generación beat. Tanto la música africana como la contracultura beat dotaron de autenticidad, identidad y rebeldía al rock. La cultura musical de África había llegado a América en los barcos de esclavos en forma de espíritus divinos y la 
rebelde generación beat había irrumpido durante los años cincuenta en los Estados Unidos.

El rock and roll jugó un papel preponderante en los movimientos culturales y sociales de los años sesenta. El movimiento hippie y la protesta pacífica contra la Guerra de Vietnam son dos mega manifestaciones que se revistieron de esta música creada por los nuevos poetas: músicos irreverentes y contestatarios a un stablishment basado en una extraña mezcla entre tradición familiar y economía de mercado. Si bien el rock and roll era una respuesta de rebeldía frente a un consumismo que crecía, pocos años después se uniría también a la tendencia de mercado liderando una industria cultural sin precedentes. Esta investigación se justifica por el alcance social y económico de una rebelde manifestación cultural frente a una sociedad cerrada y llena de prejuicios.

El rock and roll brotó de los blues en los Estados Unidos durante los años cincuenta, fue reinventado en Inglaterra a inicios de los sesenta para regarse posteriormente por todo el mundo. Esta manifestación social, cultural y económica nació tal vez como una moda, pero se quedó en el mundo para siempre. El rock and roll se transformó en rock y se esparció por el mundo mezclándose con todo tipo manifestaciones musicales y culturales. Se habla incluso del rock como una forma de vida.

En este momento nos preguntamos si ¿fue la generación beat el puente que permitió a la música negra ser una expresión de rebeldía encarnada en una música popular conocida como rock and roll? Para lo cual contestamos a manera de hipótesis, la generación beat es el puente de rebeldía entre la música negra y el rock and roll.

Esto nos hace pensar en un objetivo general: rastrear la influencia $-\mathrm{o}$ al menos coincidencia, conexión o adhesión- entre la generación beat de Kerouac, Ginsberg y Burroughs en el movimiento contracultural de la época. Y en objetivos específicos como a) identificar la incidencia, coincidencia o conexión de la contracultura en el rock and roll y en el desarrollo de la economía musical de mercado, b) describir el puente entre la cultura musical negra, la contracultura beat y el naciente rock and roll y c) detallar los vínculos entre la contracultura de los cincuenta, la rebeldía juvenil de los sesenta, el movimiento hippie, el movimiento pacifista contra la Guerra de Vietnam y la consolidación de la música y cultura rock.

El estudio se divide en las siguientes secciones: 1) La cultura africana llega a América, 2) Los blues y el jazz, 3) Los orígenes de la generación beat, 4) La contracultura beat, 5) El rock and roll nace de la negritud y de la rebeldía, 6) La música rock coincide con la contracultura beat, y 7) Conclusiones.

En cuanto al marco teórico y conceptual se ha elegido utilizar el relato histórico combinado con análisis textual. Para ello serán de mucha utilidad lo libros de los escritores de generación beat, Kerouac, Ginsberg y Burroughs principalmente, y otros textos de autores precursores de esta poética de mediados del siglo veinte, entre ellos 
William Blake, Walt Whitman y Aldous Huxley. También se recurrirá a las letras (lyrics) de determinados temas emblemáticos del rock para el respectivo análisis textual.

El marco metodológico se basa en un análisis discursivo para rastrear la relación entre la poética beat y el rock and roll. Esta metodología de análisis viene de la lingüística moderna, cuyo referente es Ferdinand de Saussure, que entiende al signo lingüístico como la unión entre un concepto o idea (significante) y una imagen acústica (significado) que se corresponden recíprocamente. Jacques Lacan ve al discurso como constituyente del lazo social, porque diferencia al humano del animal mediante el uso del lenguaje (Gutiérrez 2004, 316-318), dice que una cultura musical es una cultura de símbolos (Lacan 1976, 580). El relato contenido en la música es un discurso verbal, visual o verbo-visual conformado por un conjunto de elementos cuyo significado constituye una historia. La música rock calza perfectamente dentro de la conceptualización del relato en la letra de la canción o lyrics, es decir, cuando una música se escribe y se convierte en poesía que acompaña al sonido de los instrumentos.

El método consiste en un estudio de análisis textual de las canciones de rock y pop y su inserción en la vida social similar al que realizaron Henard y Rossetti (2014) en "All You Need is Love? Communication Insights from Pop Music's Number-One Hits". Henard y Rossetti hacen un análisis textual de las letras de los 100 éxitos publicados anualmente en Billboard Magazine durante cincuenta años, pero amplían su estudio con una herramienta de análisis de texto llamada Centering-Resonance Analysis, (CRA) similar a la $L I W C$, pero tal vez más adecuada para lyrics de canciones. Esta herramienta va más allá del análisis textual porque ordena los datos, los codifica y finalmente analiza textualmente la anáfora ${ }^{\mathrm{ii}}$, aspecto recurrente en el rock.

Para rastrear con este método la incidencia, influencia, correlación o coincidencia entre la generación beat y los inicios del rock and roll para este artículo se recurre a los listados de hits de la revista Billboard durante la década 1958-1967. Se analizarán las lyrics o letras de los aproximadamente 500 temas más escuchados entre 1958 y 1967. Se buscarán las palabras que más se repiten en cada año y se identificarán los temas comunicacionales relacionados, para después encontrar su relación con la temática beat ${ }^{2}$.

\section{La cultura africana llega a América}

El principal precursor del rock and roll llegó a América en los mismos barcos de esclavos, en forma de los espíritus divinos de Jok, Ngun, Ngundeng, Ruhanga, Ngewo, Nhialich, Onyane, Ngai, Murungo, Mungu o Nkosi, porque

[...] los pueblos africanos tienen dioses: los acholi a Jok, los barí a Ngun, los nuer a Ngundeng, los banyoro a Ruhanga, los mende a Ngewo, los dinka a Nhialich -que siendo un dios celeste es similar al Olorun de los yoruba-, los akan a Onyame, los maasai a Ngai, los agikuyu a Murungu, los swahili a Mungu, los zulúes a Nkosi [...] (Loliyong 1991, 498).

\footnotetext{
${ }^{2}$ Quiero agradecer a María Emilia Ortiz Mulé por el minucioso trabajo de rastreo de las palabras más repetidas en más de quinientas canciones top de Billboard Magazine.
} 
Dioses que acompañaron a hombres, mujeres y niños que arribaron al nuevo continente con sus religiones, cultura y ancestro africano. No hay cifras exactas del comercio esclavista, pero se estima que entre doce y catorce millones de africanos llegaron a América (Curtin 1969, 5-13). Sin embargo, se calcula que, de cada cuatro esclavos cazados -literalmente- en África, aproximadamente tres murieron en el trayecto. Es uno de los más brutales crímenes de lesa humanidad perpetrado, pero favorable a la consolidación imperial de ingleses, franceses, holandeses, españoles, belgas y portugueses.

Desde el cautiverio en sus mazmorras, los africanos y sus descendientes han sido fundamento de la historia cultural de América. Entre otras tantas cosas, son de origen africano la identidad brasileña, los ritmos caribeños y la agroindustria y música estadounidenses. La población negra americana dio hasta la vida para el progreso de un continente extraño, al que fue traída contra su voluntad y bajo condiciones inhumanas. Sin embargo, su enorme potencial cultural estuvo oculto durante siglos, hasta que la religión y la música le permitieron mostrarse en América. Parecería que la mejor forma de escapar a la opresión fue su supuesta adhesión al cristianismo, ya que gracias al adoctrinamiento religioso recibieron cualquier cantidad de ritos que les permitieron conservar secretamente sus religiones ancestrales y expresarlas mediante rituales simbólicos que poco a poco se fueron transformando en cultura musical: de las work songs, los field hollers y los spirituals ${ }^{\mathrm{iii}}$ a los variados ritmos musicales a lo largo de América: blues, jazz, rock and roll, salsa, cumbia, samba, etc.

Este sincretismo religioso permitió a los dominados africanos identificar a sus deidades con los santos de la religión dominante adaptando ritos y ceremonias. La cosmovisión religiosa africana supo asimilar al Dios y a los santos del catolicismo de los conquistadores dándoles equivalencias en sus rituales, imágenes y credos, y así la cultura africana se instaló en América para después transformarse en diferentes músicas.

\section{Los blues y el jazz}

La historia musical del África es antigua, cuando se luchaba por territorios y poder, cuando las hazañas militares no se escribían en libros, sino que eran narradas y cantadas por los trovadores africanos de la época, los griots. Yehudi Menuhin ${ }^{\text {iv }}$ decía que "los africanos tienen razón, la música es magia, magia que nos pone en contacto con los espíritus del pasado, y también del futuro". ${ }^{\mathrm{v}}$ Los ritmos de guerra y cacería, los rituales espirituales y la expresión sobrenatural han estado presentes a lo largo de la historia africana, una historia de explotación, tristeza y lamento. La primera música africana desplegada en América fueron los blues:

Claro está que los blues existían mucho antes que el jazz: al menos desde mediados del siglo pasado [el diecinueve]. Ya entonces se cantaba el blues en los distritos rurales del sur de los Estados Unidos [...] Algunos intérpretes de blues iban de pueblo en pueblo, de plantación en plantación con su banjo o su guitarra y sus pobres pertenencias y cantaban sus sencillos blues-folksongs con sonidos alargados y "mal" entonados, que se designan hoy como "blues rurales o arcaicos" (Berendt 1994, 31-32). 
Así como los bluseros iban cantando de plantación en plantación en el sur algodonero de los Estados Unidos, la representación anterior a los blues también era itinerante, tipo circo. Los minstrel shows -espectáculos de juglares o ministrilesexhibían actores blancos maquillados como negros para burlarse con bailes, chistes de mal gusto e imitaciones desmedidas de la música africana. El nacimiento del minstrel show data de 1843 cuando aparecían grupos de artistas -músicos, bailarines, magos y comediantes- en Nueva York. Estos espectáculos tenían nombres como Negro songs and dances y exhibían ridículos personajes ficticios como Zip Coon y Jim Crow ${ }^{\mathrm{vi}}$ (Springhall 2008, 57-62). Los primeros empresarios de estos espectáculos eran inmigrantes europeos de origen rural, por lo que la música en las presentaciones era una mala mezcla de danzas rurales europeas con bailes de indígenas norteamericanos y algo de tambores africanos. Los personajes eran tontos, holgazanes y borrachos, lo cual hizo que a los afroamericanos se les atribuyera una fama de ociosos que perdura hasta hoy.

Pero no hay mal que por bien no venga. Estas mofas se fueron transformando en shows de música negra. Los afronorteamericanos no dominaban los instrumentos de viento y tampoco habían podido desarrollar a fondo la percusión debido a la arbitraria limitación de tambores. Entonces, solían acompañar sus cantos con banjos y guitarras viejas con menos cuerdas. Y como no sabían afinarlas, lograron suplir esa deficiencia técnica con base en una tenaz experimentación. Así inventaron acordes y sonidos ajenos al pentagrama, a manera de prolongaciones de sus voces.

Pero si se quiere de alguna manera hallar el año de aparición de los blues, hay que remitirse al músico W.C. Handy, que en 1903 se viajó al sur, hacia el delta del Mississippi, hacia los blues (Gioia 2010, 37-38). Una noche, mientras esperaba un tren en un pueblito de Mississippi, escuchó un sonido extraño, un sonido que cambiaría para siempre la historia musical de occidente:

Un negro flaco y ágil había empezado a tocar guitarra detrás de mí mientras yo dormía [...] Su ropa estaba hecha jirones; los dedos de los pies le asomaban por los agujeros de los zapatos. Su rostro reflejaba una especie de tristeza antigua. Cuando tocaba apretaba un cuchillo contra las cuerdas de la guitarra, de un modo que [después] popularizaron los guitarristas hawaianos que empleaban una barra de acero. [...] El efecto fue inolvidable. Su canción también me cautivó de inmediato. La letra era simple y evocadora. El cantante decía tres veces la frase "Goin' where the Southern cross' the Dog" [Voy donde el sureño se cruza con el perro], acompañándose con la guitarra con la música más rara que yo había oído jamás (Gioia 2010, 38-39).

Ese extraño sonido de la guitarra se conocería después como slide (deslizamiento de un objeto por las cuerdas recorriendo el espacio entre nota y nota) y el estribillo "voy donde el sureño se cruza con el perro" se refería simplemente a viajar donde se cruzan la Southern Railway y la Yazoo Delta Railroad. Southern era la línea de tren Southern Railway que operaba entre Washington y New Orleans y the Yaller Dawg (perro aullador) era la línea Yazoo Delta Railroad por sus iniciales YD (Gioia 2010, 39).

A fines del siglo diecinueve e inicios del veinte se fortalecían los blues, de manera coincidente con la consolidación de los Estados Unidos como país y potencia mundial. 
En este contexto de hegemonía política y bonanza económica se establecía esta música afro estadounidense como auténtica y ya no como cualquier espectáculo. Para ello influyó también el belicismo. La Guerra de 1895 en la que Cuba se independizaba de España contó con el apoyo estadounidense. En este conflicto también participaron soldados negros estadounidenses, que después regresaron a su país con novedosos instrumentos y sonidos caribeños para alimentar a los incipientes blues y jazz. La adquisición más importante era la guitarra, instrumento español que suplantaría al banjo, de origen africano, para acompañar las voces en la interpretación de los blues. De esta "importación" musical-cultural hay evidencia sobre todo en New Orleans en plena cuenca del Mississippi (López Poy 2009, 72).

El jazz también nace en New Orleans, ciudad con una geografía privilegiada y estratégica para el comercio exterior, pero también con una gran heterogeneidad cultural, aspecto que facilitó la germinación de una nueva gran música. Luisiana fue colonia francesa entre 1682 y 1762, año en que fue cedida a España, que recién en 1768 tuvo pleno dominio colonial (Zinn 2011). Francia recuperó Luisiana en 1800 para intentar cumplir el sueño napoleónico de un imperio americano, sueño que se truncó por una gran insurrección de esclavos en Saint Domingue (Haití) ${ }^{\mathrm{vii}}$. Si bien el entonces presidente de los Estados Unidos, Thomas Jefferson, quería adquirir la ciudad de Nueva Orleans, en 1801 Francia le vendió todo el distrito de Luisiana en quince millones de dólares,

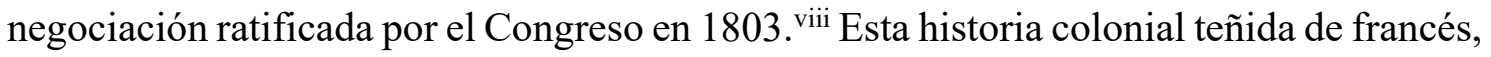
español y anglosajón engendraría una población heterogénea con ancestro francés, español, alemán, irlandés, africano (libre y esclavo) y estadounidense (colono e indio). En esta Luisiana multicultural se acuñaría el término creole -criollo en español- que significa nacido en Luisiana y descendiente de colonos, sin importar su origen étnico, sea este europeo, africano libre, africano esclavo o de origen mixto (Gilder Lehrman Institute 2014, 5). El creole sería fundamental para el nacimiento del jazz.

La guerra de Secesión entre 1861 y 1865 dejó una herencia de instrumentos musicales de percusión y viento que se remataban a precios bajos para que la ancestral música negra adquiriera, además de los cantos de trabajo y los espirituales, los ritmos militares de la guerra. "Así, los negros se encontraron en posesión de trombones, cornetas, clarinetes, tubas y tambores [occidentales], lo que aumentó su capacidad de evolucionar musicalmente" (López Poy 2009, 45-46). En un principio las bandas negras acompañaban las marchas fúnebres de la Luisiana de la época, que iniciaban con un ritmo marcial lento y acompasado para finalmente transfigurarse en una explosión rítmica (López Poy 2009, 48). Esta nueva posibilidad de improvisación viabilizó la aparición del principal antecesor del jazz, el ragtime.

El ragtime surge de una extraña mezcla de ritmos africanos provenientes del minstrel show y de ritmos europeos derivados de marchas, polcas, cuadrillas y otras melodías europeas de moda. Estos ritmos europeos se interpretaban con el banjo del minstrel show y con los nuevos instrumentos heredados de las bandas de guerra. El resultado, que incorpora ritmos europeos y podría considerarse como evidencia de un proceso de aculturación, más bien es una etapa fundamental en el progreso de la música 
afronorteamericana hacia el establecimiento de un estilo auténtico. En lugar de europeizarse la música, esta desembocó en los blues y posteriormente en el jazz.

En algún burdel de esta New Orleans de diversidad cultural nace una música hija de espirituales, canciones religiosas y marchas militares. ¿Es el jazz un hijo de madre prostituta y padre militar? De acuerdo a Rius - escritor, caricaturista y dibujante de comics- sí que lo es (Del Río 2010, 15).

Este primer jazz, nacido en la zona de tolerancia de la New Orleans de principios del siglo veinte, es conocido como el estilo New Orleans y se caracteriza por canciones populares blancas a ritmo de ragtime con un alto contenido de blues. Esta música bailable es interpretada por bandas cortas de piano, corneta, clarinete, trombón y algo de percusión, integradas solamente por afroamericanos.

Justamente en esos años, los Estados Unidos decidieron participar en la Primera Guerra Mundial. Transformaron entonces a la pecaminosa ciudad de New Orleans en una ciudad puritana para que funcionara allí una gran base naval. Se clausuraron bares, prostíbulos, salones de baile y demás lugares de diversión, y todo porque alguna autoridad militar pensó que la licenciosa vida del célebre barrio de Storyville podía inducir al pecado a los soldados que venían a radicarse en New Orleans. Esta sincera preocupación por cuidar la moral de las tropas dejó en el desempleo a muchas personas del principal puerto del Mississippi.

Meretrices, proxenetas, saloneros, meseras y ¡músicos! se quedaron en la calle. Pero los bluseros y los jazzistas iniciaron la gran migración musical a Chicago. Este desplazamiento de músicos no era más que un ejemplo puntual de la migración generalizada de afroestadounidenses desde el sur hacia el norte (Berendt 1994, 32). Con este cambio de sede se inauguraba la gran década del jazz clásico, los turbulentos años veinte y el renacimiento negro (López Poy 2009, 89). Una década que se iniciaba con la promulgación de la famosa Volstead Law o Ley Seca que prohibía todas las actividades relacionadas con el alcohol etílico ix Pero esos años locos fueron la "época del jazz" como la bautizó el escritor estadounidense F. Scott Fitzgerald en su artículo "Echoes of the Jazz Age" (1931), pero también fue la década de los gánsteres, del alcohol ilegal y de las drogas. En Chicago y en New York se desarrollaba el jazz clásico en ambientes etílicos y en medio de disputas mafiosas. Es claro que durante esos años los blues y el jazz estaban entrelazados como una sola cosa, eran una misma expresión de tristeza y melancolía, eran el mismo lamento, aunque cada vez con más recursos instrumentales, mayor cúmulo cultural y nuevas condiciones para su desarrollo.

Pero pronto el canto folklorizante de blues "rurales" desembocó en la corriente principal de la música de jazz, y desde entonces los blues y el jazz se entretejen de tal manera que Ernest Bornemann ${ }^{\mathrm{x}}$ pudo escribir que todo el jazz no era sino una aplicación del blues a la música europea o, a la inversa, la aplicación de la música europea al blues (Berendt 1994, 32).

Repuntaron entonces jazzistas como Louis Armstrong, Billie Holiday y Ella Fitzgerald, cuya música fue tan seductora que los músicos blancos también se interesaron 
y empezaron a hacer jazz. El estilo blanco tal vez era más técnico, pero definitivamente menos auténtico. En un principio la llamaban Dixieland jazz, tenía swing y era bailable, tan bailable que degeneró en el charleston, el baile más popular de los años veinte en los Estados Unidos, a ritmo de jazz, pero muy enérgico. Su nombre se debe a la ciudad portuaria de Charleston en Carolina del Sur. Es posible que esta música bailable se haya inventado para de alguna manera contener la salvaje corriente que generaba la música negra. En los años treinta este white jazz desembocaría en el Swing, por lo general interpretado por las Big Bands.

Sin embargo, desde los años cincuenta el jazz recuperaría su origen negro. Virtuosos músicos dieron a luz al bebop jazz y al free jazz. Charlie Parker, Dizzi Gillespie, John Coltrane, Miles Davis, Cecil Taylor, Ornette Coleman y todos los mágicos, rebeldes y radicales creadores de esa gama de estilos jazzísticos durante los cuarenta, cincuenta y sesenta marcaron una nueva era en la música popular, porque si bien el rock and roll sería reconocido como el hijo de los blues, es claro que también se nutrió de la brillantez, la sencillez, la espontaneidad, la improvisación, la electricidad e incluso la política contenidas en esta rebelde y espléndida expresión musical y cultural llamada jazz. Además, la conformación de grupos cortos de cuatro, cinco o seis miembros es una característica acogida por la naciente avalancha llamada rock, sobre todo en la Gran Bretaña, donde se destaca el grupo más que el solista, a diferencia de los Estados Unidos, donde es el solista el que suele predominar sobre la banda.

\section{Los orígenes de la generación beat}

La generación beat se nutre de poetas y poetisas estadounidenses del siglo veinte, que habían acudido a la convocatoria de autenticidad del poeta decimonónico Walt Whitman. Epíclesis válida también para los músicos populares del siglo veinte:

¡Poetas del futuro! ¡Oradores, cantantes y músicos futuros! No es el presente el que me justifica ni me asegura para qué existo. Pero son ustedes, una nueva raza, autóctona, recia, continental, formidable. ¡Arriba! Porque ustedes me justificarán. Lo único que yo hago es escribir una o dos palabras para el futuro, solamente me adelanto un instante para volver rápidamente a la oscuridad. Yo soy un hombre, un vagabundo, que sin detenerme totalmente, proyecto una mirada fugaz sobre ustedes y paso de largo. Y les transmito un encargo para probarlo y definirlo, esperando de ustedes la realización de la obra magnífica ${ }^{\mathrm{xi}}$.

De acuerdo a The Columbia History of American Poetry (Parini 1993), la historia de la poesía estadounidense tiene algo más de tres siglos y medio de edad y está caracterizada por una gran variedad de tendencias. En un inicio, imitativa de la británica y durante la colonia metafísica y devocional. Aún durante el siglo dieciocho los poetas estadounidenses seguían conectados a las formas inglesas. Sin embargo, en el siglo diecinueve empezaron a revelar una identidad nacional que hizo que en el siglo veinte pudieran mostrar un alto nivel de calidad. 
Durante la primera mitad del siglo diecinueve la poesía se volvió atrevida, empezando con Edgar Allan Poe (1809-1849), poeta, cuentista y crítico, consumidor de láudano ${ }^{x i i}$ (Parini 1993, 172-202) y "responsable indirecto de la aparición de una figura en el panorama literario: el poeta consumidor de drogas [...] [además] logró convencer a Baudelaire, que empezó a experimentar con drogas" (Cook 2011, 227). También en esos años eran populares los llamados Fireside Poets (poetas hogareños). Entre ellos, Ralph Waldo Emerson (1803-1882), poeta, profesor de Harvard, filósofo, pastor protestante y primer trascendentalista ${ }^{\text {xiii }}$ norteamericano (Parini 1993, xiv-xvi, 98, 582), Walt Whitman (1819-1892), que además de poeta era aficionado a la imprenta, en 1855 escribió - ¡editó e imprimió! - Leaves of grass (Hojas de hierba), un texto simbólico, alegórico y meditativo que exalta el mundo material e influye en la generación beat (Cook 2011,148171).

El período modernista (1900-1945) es tal vez el más fructífero de la historia de la poesía estadounidense (Parini 1993, 233-283). En 1912 Harriet Monroe $^{\mathrm{xiv}}$ fundó en Chicago la revista Poetry: A Magazine of Verse, una prestigiosa publicación sobre poesía. Durante los años veinte aparece la teoría imaginista, caracterizada por el uso de lenguaje común y verso libre para expresar temas mundanos. En esta escuela de poesía destacan Ezra Pound, Thomas Stearns Eliot, William Carlos Williams, H.D. (Hilda Doolittle) y poetas vinculados al Harlem Reinassance, el primer movimiento artístico importante creado por afronorteamericanos (Parini 1993, 452-476).

Regresando en el tiempo un par de siglos para rastrear el origen de esta poética, se descubre en el viejo mundo al verdadero progenitor de los poetas decimonónicos y de los rebeldes de los cincuenta y sesenta del siglo veinte. El londinense William Blake (1757-1827), pintor, ilustrador y poeta. Para unos es un místico y para otros un esquizofrénico. Con base en sus visiones construye una especie de mitología personal presente a lo largo de su obra, la combina con la religión y armoniza la prosa y la poesía con sus dibujos y grabados, mostrándose como un artista "multimedia". Su principal obra es El matrimonio del cielo y el infierno (1793), en la que rechaza cualquier religión convencional y advierte sobre el infierno y la extinción de la moral de los burgueses. Muy leído durante el siglo veinte, con seguridad por los poetas de la generación beat, de quienes fue una inspiración (Gilchrist 1998). Muchos años después, Aldous Huxley (1894-1963) utilizaría el inicio de un párrafo de El matrimonio del cielo y el infierno como nombre de uno de sus libros más famosos, Las puertas de la percepción (1954) que, a su vez, inspiraría a Jim Morrison para bautizar a su grupo de rock The Doors. "Si las puertas de la percepción se depurasen, todo aparecería al hombre como realmente es: infinito." (Blake 1906, 26). ${ }^{\mathrm{x}}$

Mirando la historia y rastreando otros precursores de la rebeldía en el viejo continente, encontramos a Thomas De Quincey (1785-1859), un británico de punzante humor, estilo evidenciado en su mordaz obra Del asesinato considerado como una de las bellas artes (1829). Su experiencia como opiómano consta en su célebre obra Confesiones de un inglés comedor de opio (1820-21) que le dio fama y lo ayudó en su mala situación 
económica (De Quincey 1994, 3-7). Su vida y obra son lo más parecido a lo vivido un siglo después por los rebeldes de la generación beat.

Y cómo no mencionar al galés Dylan Thomas (Thomas 1981), nacido en Swansea en 1914 y fallecido en New York en 1953, justamente una década antes de la primera visita de los Beatles a los Estados Unidos. A los dieciséis años Thomas abandonaba la escuela para dedicarse al periodismo y a escribir poesía, teatro y novela. En una entrevista a EFE, su nieta Hannah Ellis lo describe como la imagen viva del rock and roll. Durante sus viajes a New York, Thomas frecuentaba los bares de la Greenwich Village, un verdadero refugio de arte, cultura y bohemia del New York de la primera mitad del siglo veinte. En la década de los cincuenta, los poetas de la generación beat también eran

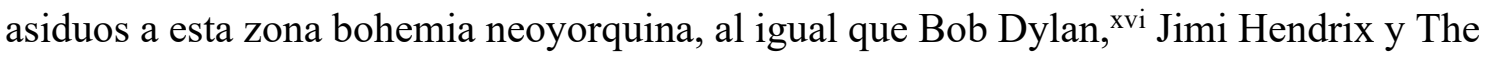
Velvet Underground a inicios de los sesenta. Son famosas las últimas palabras de Thomas: "He bebido dieciocho vasos de whisky. Creo que es todo un récord" (Jurado Morales 2012, 129) para enseguida caer en un coma etílico que lo mataría antes de cumplir cuarenta años. De la misma manera que Dylan Thomas, algunos miembros de la generación beat fueron víctimas de la fama, la bohemia y los excesos. El poeta y cantautor canadiense Leonard Cohen dijo alguna vez de Thomas, "fue la gran voz de la poesía cuando estaba en la universidad. Nosotros [los jóvenes poetas] estábamos intrigados con su fama, su genio, su bebida y su sentido incondicional de la irresponsabilidad social".xvii

\section{La contracultura beat}

La semilla sembrada por los mencionados escritores, ensayistas y poetas germinó en la imaginación de intelectuales, escritores, poetas y novelistas de la generación beat y, por transitiva, con los músicos de las décadas de los sesenta y setenta, tanto en los Estados Unidos como en la Gran Bretaña. Los principales aspectos de influencia, incidencia, coincidencia o adhesión, son la rebeldía juvenil, el rechazo al establishment, el uso de alcohol y otras drogas, la permanente protesta ante las autoridades -familiares, religiosas y políticas- y la constante búsqueda de paz y amor.

El término beat alude al compás musical, pero también significa cansado o abatido, síntomas indudables dentro de un grupo de escritores que influenciarían al movimiento hippie. Un grupo de depresivos desencantados del American dream, quizá alineados con la izquierda, consumidores de alcohol y drogas, simpatizantes del misticismo oriental, pioneros en la defensa de la diversidad sexual y tan audaces como los vanguardistas de inicios del siglo veinte.

Los estadounidenses de la generación anterior eran incapaces de entender a estos jóvenes que no trabajaban a pesar la gran disponibilidad de buenos trabajos. No comprendían el porqué de su rechazo a la nueva abundancia disponible en los Estados Unidos. Estos radicales eran los beat. En un artículo de la revista Rolling Stone en conmemoración de los sesenta años de la generación beat, el autor los caracteriza muy acertadamente, “[...] recordamos la historia de una banda de vagabundos místicos, bellos asesinos, libertarios existencialistas y poetas que aullaron contra la moral burguesa de 
posguerra" (Rebollo 2012,38). Esta generación dejaría su impronta en la contracultura y en el posterior movimiento hippie. Uno de ellos -Allen Ginsberg- decía que "las propuestas de lo que se llamó generación beat fueron: apostar por el candor, por la ecología, por el pensamiento oriental, la revolución sexual y la exploración de la mente por medio de drogas psicodélicas". ${ }^{\text {xiii }}$ La expresión beat surge de una charla entre Jack Kerouac y John Clellon Holmes a fines de la década de 1940, inspirados en Herbert Huncke, $^{\mathrm{xix}}$ un yonqui ${ }^{\mathrm{xx}}$ de New York, que según la opinión de Lydia Lunch $^{\mathrm{xx}} \mathrm{y}$ de muchos otros "era el beat original. Él inventó el jodido término...ese del que el trío de pecadores de Burroughs, Ginsberg \& Kerouac se aprovecharían toda la vida" (Lunch 1998). Pero es gracias a un artículo del propio Holmes titulado "This is the Beat Generation" (New York Times Magazine, November 16, 1952) que se difunde el término, vinculándolo con los significados "golpe", "latido" y "ritmo", pero extendiendo su significado:

Si bien el origen de la palabra 'beat' no es muy claro, su significado es clarísimo para la mayoría de los estadounidenses. Más que sentirse abatido [beat] implica una sensación de haber sido utilizado, manipulado. Implica una especie de desnudez de la mente y, en última instancia, del alma; una sensación de haber llegado al fondo de la conciencia. En pocas palabras, [beat] significa haber sido empujado sin dramatismo contra la pared de uno mismo $[\ldots]^{x x i i}$.

Sin embargo, a manera de reacción ante estos radicales, un periodista del San Francisco Chronicle, Herb Caen, inventó el despectivo término beatnik -una combinación entre beat y el satélite soviético Sputnik- para sugerir que se trataba de un grupo comunista y anti-estadounidense (Huddleston 2012, 10). También se cuenta que J. E. Hoover -fundador y eterno director del FBI- había dicho en la Convención Republicana de 1960 que los beatniks eran una de las tres amenazas de los Estados Unidos, junto con el comunismo y los intelectuales, a quienes despectivamente llamaba eggheads $^{\mathrm{xxiii}}$ (Huddleston 2012, 8). Por ello, a fines de esa década Jack Kerouac creyó conveniente sugerir un significado diferente al término beat y en vez de abatido o golpeado habló de "beatífico" porque el movimiento estaba atraído por la naturaleza, la meditación y el pensamiento oriental. Sin embargo, en defensa de este movimiento fuera de lo común, genuino y auténtico, se puede decir que los intelectuales de la generación beat, más que beatniks fueron hipsters, ${ }^{\text {xiv }}$ es decir, personas con gustos musicales diferentes a aquellos considerados adecuados para la correcta sociedad estadounidense de los años cincuenta. A estos nuevos hipsters les gustaba el jazz y también arrogarse costumbres, modos de vida e incluso el lenguaje afronorteamericano, razones suficientes para ser mal vistos. Precisamente el citado paper "The Beat Generation: They Were Hipsters Not Beatniks" de Diane Huddleston (2012) explica por qué los miembros del movimiento beat no deben ser llamados beatniks.

El legado de los beats es enorme en varios aspectos, en literatura, política, sociedad, contracultura y música popular, fundamentalmente en lo referente a estética y autenticidad. Pero para de alguna manera entender mejor lo que ha significado este movimiento, es más inteligible analizar por separado algo de la vida y obra de cada uno de los referentes beats. 
Si hay una fecha oficial de la presentación oficial del movimiento beat, esa sería el 7 de octubre de 1955, cuando Kenneth Rexroth organizó la velada poéticarevolucionaria Six Poets at Six Gallery. El público -incitado por Kerouac- festeja a rabiar a Ginsberg cuando recita (¿aúlla?) su largo poema Howl, y finalmente Snyder cierra la noche leyendo "A Berry Party" a manera de ritual tribal (Suiter 2008, 20-25). Hay que señalar que McClure solía presentar su poesía con acompañamiento musical, sobre todo con el minimalista Terry Riley, además de haber grabado varios discos con el tecladista de The Doors, Ray Manzarek. Si bien la presentación oficial de los beat fue en la Six Gallery de San Francisco en 1955, el movimiento había nacido once años antes en Manhattan cuando se conocieron Kerouac, Ginsberg y Burroughs.

\section{El rock and roll nace de la negritud y de la rebeldía}

Si bien es innegable que el rock and roll nace de los blues, no es menos cierto que hubo otros ritmos y compases que formaron parte de esta suculenta receta musical. El jazz es fundamental por la rebeldía, la espontaneidad, la improvisación y la novedosa integración del grupo musical: entre cuatro y seis performers en lugar de los casi veinte de las bandas del Swing.

Chuck Berry, Little Richard y Elvis Presley "inventaron" el rock and roll, mientras que los británicos se fundamentaron en el skiffle, el free jazz y la rebelde guitarra de los blues para fundar un rhythm and blues revival que invadiría al mundo entero.

Charles Edward Anderson "Chuck" Berry (1926), de St. Louis Missouri, es quien arma el rompecabezas de ruidos, compases y ritmos, y a partir de su irrupción se desarrolla este explosivo producto cultural. Los Rolling Stones son sus discípulos declarados y según John Lennon, el rock and roll bien debería llamarse Chuck Berry.

Little Richard es otro grande en los albores del rock and roll. Nacido en 1932 en Macon, Georgia como Richard Wayne Penniman. Cantante, compositor y pianista producto de una familia religiosa de la comunidad de los Adventistas del Séptimo Día (Sierra i Fabra 2003, 35-36).

El 8 de enero de 1935 en Tupelo, Mississippi, poco antes del amanecer, en una pequeña casa de dos habitaciones construida por Vernon Presley, su esposa Gladys da a luz a mellizos. El primero, Jessie Garon, nace muerto, el segundo, Elvis Aaron, nace vivo y saludable. Elvis crece en una familia de clase trabajadora, sus abuelos, tías, tíos y primos viven cerca. No hay dinero, pero sus padres hacen un gran esfuerzo por criarlo. Desde niño gusta de la música y canta góspel en la iglesia a la que asisten, también escucha en la radio los blues interpretados por cantantes negros y la música pop de la época. Cuando cumple once años sus padres le regalan una guitarra. A sus trece años su familia se muda a Memphis, Tennessee. El 5 de julio de 1954 se reúne con unos músicos locales en el mismo lugar de grabación para ensayar con el productor de Sun Records, Sam Phillips. ${ }^{\text {xxv }}$ Después de interpretar algunas canciones poco interesantes para el productor, el grupo se toma un descanso. Pero Elvis decide no descansar y se lanza con una versión acelerada de "That's All Right" de Arthur Crudup. Los otros músicos se juntan enseguida y Sam 
Phillips finalmente escucha lo que estaba buscando. Phillips graba esta versión que se convierte el primer single de Elvis, pero con el título "That's All Right, Mama" que, según muchos, es el primer tema rock'n'roll de la historia (Bogdanov et al. 2002, 880884). A pesar que el rock and roll estaba en franco proceso de formulación, la fulgurante aparición de Elvis en 1956 puede considerarse como el punto de inflexión del proceso de transformación de la música popular.

De no haber sido por Elvis, posiblemente el rock and roll no habría llegado tan lejos en el tiempo. Es claro que hubo otros talentosos rocanroleros en los inicios de esta maravillosa expresión cultural-musical, como Fats Domino, los mencionados Berry y Richard, Bill Haley, Jerry Lee Lewis y Buddy Holly, principalmente.

Pero este nuevo ritmo nacido en los Estados Unidos decaería por algunas causas puntuales a fines de los años cincuenta. Si bien la erupción rocanrolera había convertido a la música popular en un fenómeno de masas y había consolidado una gran industria musical, vendrían los tropezones artísticos de algunos de los grandes. Si bien Elvis estaba en la cima, había sucumbido ante el pudor estadounidense, tanto así que luego de sus éxitos rocanroleros grababa villancicos y música melosa. Parece insólito que la canción más vendida de la historia del rey del rock sea una versión en inglés del famoso tema italiano "O Sole Mio" (Sierra i Fabra 2003, 47). Elvis perfeccionaría su desliz marchando al ejército como un auténtico American hero. Chuck Berry pagaría su arrogancia y sus torcidas preferencias por chicas menores de edad al ser condenado a tres años de reclusión por pederastia. Little Richard había descubierto que su vida no era más que una sucesión de graves pecados - alcohol, drogas y homosexualidad-y tenía que retirarse de la música satisfacer a Dios y recibir la indulgencia divina.

Luego de un brillante lustro en lo cultural y, sobre todo en lo económico, el rock and roll decaía en los Estados Unidos y empezaban a recuperar su espacio los cantantes de la traditional pop, dueños de voces sonoras y acompañados por grandes orquestas. Es el caso de Frank Sinatra, Bing Crosby, Dean Martin, Perry Como, Nat King Cole y Matt Monro, entre otros.

Menguaba el rock'n'roll en los Estados Unidos y aparecía un último intento por "civilizarlo" comercialmente mediante la creación de un baile algo erótico pero lo suficientemente sano como para calzar en la implacable y puritana horma del American Way of Life. El Twist es un baile alocado nacido del rock and roll que aparece a principios de los sesenta con una canción llamada "The Twist" compuesta por Hank Ballard en 1959 pero popularizada por Chubby Checker en 1960 (Scaruffi 2007, 17). Como para corroborar la extinción -temporal- del rock and roll en los Estados Unidos, se puede decir que a fines de los años cincuenta el tema más vendido y escuchado en ese país era "Nel Blu Dipinto di Blue (Volare)" del italiano Domenico Modugno (Whitburn 2010, 448).

Pero parecería que la sociedad del Viejo Mundo sí estaba lista para esta revolución cultural. El salvaje y pecaminoso rock and roll renacería en Inglaterra de la misma negritud de los blues y del free jazz. Eric Hobsbawm ${ }^{\mathrm{xxvi}}$ ofrece buenas pistas sobre la llegada del jazz a Inglaterra y sobre su incidencia cultural y política en el sesentero british 
rhythm \& blues revival o rock británico. La afición de Hobsbawm por el jazz había empezado durante la Segunda Guerra Mundial, época de vanguardias anti nazistas y de intelectuales melómanos que escuchaban jazz tradicional - hot jazz-en los cafés durante la tarde y en los pubs en la noche que poco a poco irían cambiándose a géneros jazzísticos menos bailables y más intelectuales como el bebop y el free jazz. Obviamente el Soho londinense era el epicentro de la bohemia jazzística.

El jazz aparece a la Gran Bretaña a principios del siglo veinte como una música bailable que enseguida sería acogida por la clase alta, la clase media y la clase obrera. En 1914 llega también el foxtrot,${ }^{\text {xxvii }}$ suceso que coincide con un cambio en las costumbres, el baile urbano ya no era solamente una práctica vinculada a ocasiones especiales, sino que se practicaba como una actividad regular relacionada con el ocio. Así, mediante una ruidosa irrupción musical ingresaba en la Gran Bretaña la cultura negra de los Estados Unidos (Hobsbawm 2013, 241-244), de la mano de los blues y de nuevas variedades de jazz. Junto con los ritmos negros llegaban también los músicos negros.

Pero además del rock and roll estadounidense y el free jazz, a mediados de los años cincuenta aparecía en Inglaterra el skiffle, un tosco estilo de música con instrumentos rudimentarios. Originalmente había surgido en los Estados Unidos en la década de 1920 yera música tocada con jarras, guitarras, banjos, armónicas y kazoos $^{\mathrm{xxviii}}$, primero en Louisville en 1905 y luego en Memphis desde los años veinte. En la empobrecida Gran Bretaña post Segunda Guerra Mundial, los jóvenes estaban felices al descubrir un estilo de música rebelde que se podía tocar con una guitarra, una tabla de lavar raspada con dedales y un bajo construido con un palo de escoba y una cuerda unida a una caja de madera. El famoso ídolo de Bob Dylan, el cantautor de folk-protesta Woody Guthrie fue un héroe popular que inspiró a muchos músicos de skiffle al otro lado del Atlántico. Cuando el cantante y banjoista escocés Lonnie Donegan abandonó en 1954 su banda de jazz tradicional para grabar una versión rápida del tema de blues "Rock Island Line" de Leadbelly, estaba sentando las bases de la música británica de los sesentas. Este disco sencillo fue comprado por millones, incluidos John Lennon y Paul McCartney, quienes recibieron así su primera exposición a la música popular afroamericana. Lennon y McCartney estaban entre los miles de jóvenes británicos que, inspirados por Donegan, formaron grupos de skiffle, en el caso de John Lennon, The Quarry Men que sería un primer paso hacia el rock and roll.

Da la sensación que la rebeldía musical británica se muestra en grupo a diferencia de la individualidad estadounidense. Los artistas norteamericanos buscan brillar solos, tal es el caso de Elvis Presley, Marlon Brando, Frank Sinatra, James Dean y tantos otros. El espíritu individualista destaca en el músico estadounidense, a excepción del jazz donde lo importante es el grupo, sobre todo en los cortos grupos del free jazz. Esta fuerza del free jazz se traslada a las bandas de rock británicas junto con el espíritu de los blues y el "desorden" del skiffle. No son pocos los músicos estadounidenses que van a Inglaterra a promover el blues-rock británico, entre ellos Muddy Waters, Jimi Hendrix y Howlin' Wolf. Con estos mensajeros de negritud nacía "la música del diablo"xxix o blues británicos, música enfocada en la banda o el grupo. Así como afirma Ted Gioa al citar al 
pionero en la preservación de la música afroamericana Alan Lomax: "[esta música] surge de un grupo en el que todos los cantantes pueden improvisar juntos, aportando cada uno algo personal a un constante efecto colectivo, una práctica habitual en las tradiciones africana y afroamericana" (Gioia 2002, 17). Es decir, la improvisación individual al servicio del éxito colectivo. El alma grupal del free jazz se inserta en el rock británico, aunque la guitarra toma el lugar del saxofón. El free jazz, entonces, viaja a Inglaterra, un jazz de bandas cortas en lugar de las big bands, es un jazz libre que había reemplazado al Swing. El gran Muddy Waters ${ }^{\mathrm{xx}}$ fue el maestro de varios rockeros ¿o bluseros? británicos: Eric Clapton, Jimmy Page, Keith Richards, entre varios otros. Es más, los grandes grupos de rock británico siempre insisten que lo de ellos es blues.

Otro aspecto a resaltar del revival británico del blues-rock es una buena convivencia con la cultura afro, había clubes y bares -o pubs- no exclusivos donde se escuchaba blues y jazz. Además, gracias a la Ley de Nacionalidad Británica de 1948 y la Constitución de Jamaica de 1962 fue enorme la afluencia de jamaiquinos a Londres y al resto del país.

Los jamaiquinos llegaban, entonces, con su color, sus rastas, su cultura y obviamente con su música. Raíces culturales y tradiciones africanas mezcladas con canciones populares europeas. Surgía el ska y se mezclaba con el soul para dar a luz al rocksteady, ritmo fundamental para la invención del reggae, la entrada de la música de Jamaica al mercado global y su gran influencia sobre el blues-rock británico.

En Londres se instalaban músicos afroamericanos, de Estados Unidos y de Jamaica con sus ritmos, para mezclarse con lo que estaba sonando. Pero en Gran Bretaña se producía algo inusual en los Estados Unidos, una coincidencia cultural entre los afroamericanos y la clase obrera británica. La interesantísima semejanza entre el ex esclavo negro y el proletario británico se entiende claramente en la canción "Working class hero" de John Lennon. La inconformidad del trabajador británico es comparable a la de un ex esclavo incorporado a la fuerza de trabajo del sistema capitalista.

Tan pronto como naces te hacen sentir pequeño [...] Te lastiman en casa y te golpean en la escuela. Te odian si eres listo y te desprecian como a un tonto, hasta que estás tan jodidamente loco que no puedes seguir sus reglas [...] Cuando te han torturado y asustado por veintitantos años, entonces esperan que escojas una carrera, pero ya no funcionas porque estás lleno de miedos [...] Te drogan con religión, sexo y televisión. Y te crees ingenioso, sin clase social y libre. Pero sigues siendo un jodido campesino. De la clase obrera un héroe hay que ser $^{\text {xxxi }}$.

John Lennon describe la melancolía y la "depre" de los bluseros -I've got the blues - que sin duda se evidencia en una suerte de contagio de los "virus" de la negritud y de la generación beat en Gran Bretaña, donde los rockers imitaban a Elvis, pero no todos se identificaban con las "rebeldes" actitudes estadounidenses. En pocos años, los bluseros británicos incorporaron locura artística y perfeccionaron los blues con una asombrosa fuerza. En los sesenta aparecían bandas diferentes como The Who, The Rolling Stones, The Yardbirds y The Animals, entre otras. 
El renacer británico del rock ayudaría a bluseros estadounidenses a convertirse en estrellas, tal es el caso de Janis Joplin y Jimi Hendrix. Este último -formado en Londreses considerado el mejor guitarrista de todos los tiempos. En la Gran Bretaña el rock era más underground, más experimental y mucho más psicodélico, encarnado por grandes bandas como Pink Floyd y Soft Machine, que suscitaban el tan extraño como magnífico progressive rock, una sub-especie con una muy interesante influencia de jazz. Es claro que el rock británico era más "europeo", con un contenido de música clásica, algo de música celta y mucho de rock-jazz. Este nuevo rock inspiraría al progressive rock, que reemplazaba la energía del primer rock and roll, pero esta vez con conceptos. Sobresalían en este aspecto Traffic, Jethro Tull y Roxy Music, con una especie de soul rock, diferente al original rock and roll. Las bandas británicas King Crimson, Genesis y Yes comienzan a componer complejas piezas teatrales y los instrumentos electrónicos se emplean cada vez con más frecuencia.

¡Los británicos habían logrado mostrar la dimensión artística del rock’n'roll, le habían dado el estatus de arte!

\section{La música rock coincide con la contracultura beat}

Pero de la misma forma como los beats miraban al mundo, los jóvenes músicos de los años cincuenta y sesenta también querían expresarse manifestando toda su rebeldía, y contagiados por el espíritu y la autenticidad de la música afronorteamericana y de esta poética, empezaron a componer y a trascender. No se podría asegurar una incidencia o una influencia, pero de seguro que existe una gran adhesión ¿o coincidencia? estética y cultural. Los blues y el jazz parieron al rock and roll, pero la autenticidad y la rebeldía poéticas también estuvieron allí.

Asimismo, parece clara la conexión con algunos grandes del rock como Bob Dylan, Janis Joplin, David Bowie, Patti Smith, Frank Zappa, The Grateful Dead, Jethro Tull, Pink Floyd, The Velvet Underground, entre otros.

Se pueden mencionar episodios de flirteo entre la generación beat y el rock, una relación cultural, estética, temporal, social e incluso comercial, que muy probablemente es el elemento que impregnó de autenticidad al rock. Ginsberg es el poeta favorito de Bob Dylan, es más, eran amigos y trabajaron juntos en algunos proyectos, entre ellos la película Don't look back, ${ }^{\text {xxxii }}$ la legendaria gira "Rolling Thunder Revue Tour" y la película producto de ella, Renaldo and Clara ${ }^{\text {xxxii }}$ A Ginsberg se lo ve en esa película leyendo su poema Kaddish y en algún break entre toma y toma, conversando con Dylan frente a la tumba de Kerouac. Se sabe que David Bowie era un gran admirador de Burroughs, las letras de sus canciones tienen la influencia estética del novelista beat, solía escribirlas a mano, con base en collages de palabras, utilizando el método cut up de Burroughs. ${ }^{\text {xxiv }}$ El artículo publicado en la revista Rolling Stone, "El Padrino Beat y el ídolo del Glitter" (Copetas 1974) a manera de conversación entre Burroughs y Bowie, es una muestra de su cercanía estética. Hablan de varios temas, política, medio ambiente, el período flower power, Kerouac, Andy Warhol. Sobre este último decía Burroughs: “[n]o 
creo que haya una persona ahí dentro. Es una cosa alienígena, completa y totalmente sin emociones. Es como un personaje de ciencia-ficción. Incluso tiene un extraño color verde". David Bowie piensa que es un tipo extraño pero que le gusta su arte. Un extraño vinculado al mercado. "La obra de Andy Warhol gira sobre todo en torno a la mercantilización, y los enormes carteles publicitarios de la botella de Coca-Cola o de la lata de sopa Campbell”' (Jameson 1991, 5).

Asimismo, en 1961 Burroughs publica la novela The Soft Machine, nombre que fue tomado por un grupo inglés de rock progresivo psicodélico y jazz-rock. La célebre Janis Joplin (1943-1970) siempre decía que Ginsberg había influido en su forma de cantar-actuar. Su tema "Mercedes Benz" es un blues escrito por Janis para ser cantado a capela. Se cuenta que ella estaba en el estudio y recordó la primera línea de una canción del poeta beat Michael McClure: “Oh Lord, won't you buy me a Mercedes-Benz?” y siguió improvisando hasta que materializó uno de los grandes éxitos de su corta carrera. De la misma manera, Van Morrison utiliza una gran cantidad de referencias literarias en las letras de sus canciones, de Blake, Rimbaud y de la generación beat, especialmente de Kerouac, a quien, junto con algunos grandes bluseros, invoca en la canción "Cleaning windows" del álbum Beautiful Vision (1982):

Oí a Leadbelly y a Blind Lemon / En la calle donde nací, Sonny Terry, Brownie McGhee / Muddy Waters cantando "I'm a Rolling Stone" / Me fui a casa para leer mi libro navideño de Humphreys sobre el Zen / La curiosidad mató al gato / "Dharma Bums" $y$ "On the Road" de Kerouac"xxxv.

También Bono, el vocalista de U2, está influenciado en las letras de las canciones, en las ideas y la forma de pensar de la generación Beat. Cuentan que uno de sus libros de cabecera es Howl de Ginsberg, quien aparece en el documental de U2 "A Year in Pop" (1997) leyendo la letra de la canción "Miami” del grupo con la melodía de fondo.

Un ejemplo de que la onda beat y el rock and roll están enganchados es el nombre del grupo de rock and roll más famoso de todos los tiempos. The Beatles viene de una combinación de beetles (escarabajos) y beat.

Para reforzar lo dicho con datos empíricos, a continuación se presenta un análisis textual para identificar los temas principales de las lyrics de varias canciones. Se ha escogido las top de la revista Billboard entre 1958 y 1967. 
Tabla 1. Análisis textual CRA de temas de rock

\begin{tabular}{|c|c|c|c|c|c|c|c|c|c|c|}
\hline \multicolumn{11}{|c|}{ Canciones \#1 según Billboard por año } \\
\hline & 1958 & 1959 & 1960 & 1961 & 1962 & 1963 & 1964 & 1965 & 1966 & 1967 \\
\hline \multirow{10}{*}{$\begin{array}{l}\text { Palabras } \\
\text { influyentes: }\end{array}$} & Amor & Amor & Amor & Nena & Niña & Amor & Amor & Amor & Amor & Amor \\
\hline & Corazón & Nena* & Hombre & Amor & Amor & Niña & Nena & Nena & Bueno & Adiós \\
\hline & Sueño & Noche & Noche & Noche & Nena & Ciudad & Ciudad & Niña & Nena & Nena \\
\hline & Vida & Ciudad & Corazón & Corazón & Corazón & Abandono & Hombre & Hombre & Noche & Noche \\
\hline & Bueno & Solitario & Beso & Beso & Noche & Mujer & Noche & Juego & Corazón & Vida \\
\hline & Noche & Ojos & Nena & Bueno & Bueno & Noche & Mundo & Bueno & Hombre & Ojos \\
\hline & Mundo & Beso & Estúpido & Hombre & Hombre & Hombre & Niña & Mundo & Niña & Niña \\
\hline & Avión & Mujer & Lágrima & Niña & Ojos & Corazón & Corazón & Noche & Mundo & Ciudad \\
\hline & Música & Niña & Vida & Lágrima & Mundo & Ojos & Lágrima & Mujer & Ciudad & Mundo \\
\hline & Niña & Vida & Mujer & Beso & Vida & Mundo & Beso & Vida & Vida & Juego \\
\hline \multicolumn{11}{|c|}{ Palabras influyentes en orden descendente. Traducidas de Table 1 (Henard y Rossetti 2014, 17). } \\
\hline
\end{tabular}

Fuente: Henard y Rossetti (2014)

La tabla 1 muestra las palabras que más se repiten en las letras de las más de quinientas top canciones publicadas por Billboard durante los primeros diez años del rock and roll.

En la tabla 2 se relacionan todas las palabras influyentes encontradas con ciertos descriptores asociados, que permiten ubicar finalmente los temas de influencia. Los temas de influencia son aquellas palabras que permiten relacionar las canciones de la época con las actitudes y costumbres de los poetas beat. Los temas comunicacionales muestran una conexión entre lo que decían y escribían los poetas beat y lo que después cantaron los rockanrolleros durante los primeros diez años del rock and roll.

Tabla 2. Temas comunicacionales, descriptores asociados y palabras de influencia

\begin{tabular}{|c|c|c|}
\hline \multicolumn{2}{|c|}{ Canciones Top 100 del rock and roll (1958-1967) } \\
\hline Temas & Descriptores asociados & Palabras influyentes \\
\hline Pérdida & $\begin{array}{c}\text { Tristeza, dolor de corazón, amor } \\
\text { perdido, soledad, romance no logrado }\end{array}$ & $\begin{array}{c}\text { Corazón, amor, solitario, abandono, } \\
\text { lágrima }\end{array}$ \\
\hline Deseo & $\begin{array}{c}\text { Anhelo, deseo, anticipo, lujuria, } \\
\text { codicia }\end{array}$ & $\begin{array}{c}\text { Noche, nena, niña, juego, esquina, baile, } \\
\text { música, vida }\end{array}$ \\
\hline
\end{tabular}




\begin{tabular}{|c|c|c|}
\hline Aspiración & $\begin{array}{c}\text { Sueños, mundano, anhelo, anticipo, } \\
\text { esperanza }\end{array}$ & $\begin{array}{c}\text { Sueño, paraíso, noche, luna, mundo, Dios, } \\
\text { memoria }\end{array}$ \\
\hline Separación & $\begin{array}{c}\text { Desamor, pérdida, separación, adiós, } \\
\text { nombre de persona }\end{array}$ & $\begin{array}{l}\text { Tiempo, abandono, lágrima, adiós, } \\
\text { solitario, avión }\end{array}$ \\
\hline Dolor & $\begin{array}{c}\text { Emociones mezcladas, ahora, tristeza, } \\
\text { cambio, adiós }\end{array}$ & $\begin{array}{l}\text { Malo, bueno, adiós, beso, mujer, hombre, } \\
\text { memoria }\end{array}$ \\
\hline Inspiración & $\begin{array}{l}\text { Optimismo, energía, vitalidad, baile, } \\
\text { conectividad }\end{array}$ & $\begin{array}{c}\text { Vida, música, bueno, mundo, baile, Dios, } \\
\text { mujer }\end{array}$ \\
\hline Nostalgia & $\begin{array}{l}\text { Romanticismo, unicidad, unión, } \\
\text { soñador, idealista }\end{array}$ & Día, mujer, corazón, paraíso, beso, ciudad \\
\hline \multicolumn{3}{|c|}{ Palabras influyentes en orden descendente. Basado en Henard y Rossetti $(2014,18)$. } \\
\hline
\end{tabular}

Fuente: Henard y Rossetti (2014)

A continuación, los temas más influyentes de cada uno de los años analizados:

Tabla 3. Temas de mayor influencia por año (1958-1967)

\begin{tabular}{|c|c|}
\hline Año & Temas influyentes \\
\hline 1958 & Pérdida, deseo, inspiración \\
\hline 1959 & Pérdida, deseo, inspiración, nostalgia \\
\hline 1960 & Dolor, pérdida, deseo, inspiración \\
\hline 1961 & Pérdida, deseo, dolor, nostalgia \\
\hline 1962 & Deseo, pérdida, nostalgia \\
\hline 1963 & Pérdida, deseo. nostalgia \\
\hline 1964 & Pérdida, deseo, dolor, nostalgia \\
\hline 1965 & Deseo, pérdida, nostalgia \\
\hline 1966 & Pérdida, dolor, aspiración \\
\hline 1967 & Pérdida, deseo, aspiración \\
\hline
\end{tabular}

Fuente: Henard y Rossetti $(2014,21)$

En términos muy generales, los diez años relatan la rebeldía, el abandono y el deseo de la época, también el dolor contenido y la amargura de la negritud que había sido asumida por la generación beat. El rock and roll, entonces, recogía el sentimiento de frustración y rebeldía de los escritores y poetas beat y establecía una nueva "poética" de rebeldía con un gran condumio de música negra y poética beat. 
A continuación, hago un análisis textual particular de algunas canciones transformadas en himnos de amor, paz y voz de la contracultura. Son expresiones de rebeldía, amor, paz y protesta contra el poder establecido. En este sentido, podemos considerar como el primer gran himno a "Blowin' in the Wind" (1963) de Bob Dylan, una canción protesta contra el sistema, enfocada en la guerra, aunque bastante pesimista.

¿Cuántos caminos debe recorrer un hombre antes de que le llamen hombre? [...] Sí, y ¿cuántas veces deben volar las balas de cañón antes de ser prohibidas para siempre? [...] Sí, y ¿cuántas muertes serán necesarias para saber que tantos mueren? [...] La respuesta, mi amigo, está soplando en el viento, la respuesta está soplando en el viento. ${ }^{\text {xxvi }}$

Pero el mismo Dylan se vuelve más explícito cuando compone en 1964 "The times they are a-changin" y la vocaliza con más feeling. La impecable narración con su típica voz áspera, acompañada de guitarra y armónica, convoca a todos al cambio social, enaltece a la juventud y exalta la libertad y la igualdad, ideales supuestamente americanos.

Vengan escritores y críticos que profetizan con su pluma [...] la oportunidad no volverá [...] Vengan senadores y congresistas, por favor atiendan a la llamada, no se queden en la puerta [...] Vengan madres y padres de todas partes y no critiquen lo que no pueden entender, sus hijos y sus hijas están fuera de su control, su antiguo modelo de formación está caducando rápidamente. Por favor, salgan del nuevo modelo si no pueden aportar $[\ldots]$ porque los tiempos están cambiando. ${ }^{\text {xxxvii }}$

Por estos y por otros varios temas como "Masters of War" (1963), "A hard rain's a gonna fall” (1963), “Chimes of Freedom" (1964), "Like a Rolling Stone” (1965), "It's alright Ma" (1965), "Just like a Woman" (1966), “Absolutely Sweet Mary" (1966), el gran Bob Dylan fue galardonado con el premio Nobel de literatura en el año 2016. La Academia Sueca dijo que "por haber creado nuevas expresiones poéticas dentro de la gran tradición de la canción estadounidense", a lo que el músico profundamente agradeció y respondió con un discurso el 10 de diciembre de 2016. "En ningún momento tuve tiempo para pensar: ‘¿Mis canciones son literatura?’ Así que agradezco a la Academia Sueca que se haya tomado el tiempo de considerar esa pregunta y, en última instancia, proveer una respuesta tan maravillosa" (www.nobelprize.org).

En julio de 1967 los Beatles lanzaban el álbum Magical Mistery Tour, LP en el que destaca una canción símbolo en la historia de la globalización cultural. "All You Need is Love" había sido compuesta para mostrar la cultura británica al mundo. La canción de John Lennon se interpretaba por primera vez el 25 de junio de 1967, transmitida en vivo vía satélite por la $B B C$ de Londres a veintiséis países para más de 400 millones de televidentes. El programa Our World era la primera transmisión televisiva global de la historia, y consistía en que catorce países se mostraban al mundo. Participaron, además de los Beatles, la cantante de ópera María Callas y el pintor Pablo Picasso. Unos exponían sus paisajes, otros sus monumentos y edificios, pero el Reino Unido mostraba a los Beatles interpretando una canción que se convertiría en un himno

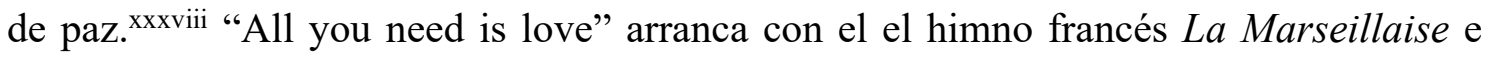
incluye partes de otros temas como la "Invención $N^{\circ} 8$ en fa mayor" de J. S. Bach, "In 
the mood" de Glenn Miller, "She loves you" y algo de "Come Together" de los propios Beatles y "Prince of Denmark's March" de Jeremiah Clarke. La primera parte de la canción es la fundamental. Después de La Marseillaise hay un coro que entona tres veces "Amor, amor, amor" hasta que entra la voz de Lennon con:

No hay nada que puedas hacer que no pueda ser hecho / Nada que puedas cantar que no pueda ser cantado / Nada que puedas decir, pero puedes aprender las reglas del juego / Es fácil / Nada que puedas hacer que no pueda ser hecho / Nadie a quien puedas salvar que no pueda ser salvado / Nada que puedas hacer, pero puedes aprender a ser tú mismo a tiempo / Es fácil / Todo lo que necesitas es amor... ${ }^{\text {xxix }}$

De esta manera, un himno a la paz se convertía también en un himno a la globalización de las comunicaciones y, por qué no, en un símbolo de la economía mundial de mercado. Musicalmente "All you need is love" es una canción sencilla, la tonada es muy simple y en sus coros solamente se percibe una nota, además, es una de las pocas canciones compuestas en el inusual tiempo $7 / 4 .{ }^{x 1}$ Poéticamente, se basa en el amor, la sencillez y en un dicho popular de aquella época de paz y amor, la década de los sesenta contra la guerra, y justamente durante el Summer of Love de 1967.

Entonces, la cultura de amor y paz es ley en los sesenta, tal como también se describe en el tema "Aquarius" del grupo The 5th Dimension. Es la canción que abre el musical Hair ${ }^{x l i}$ y encarna la espiritualidad del movimiento hippie de la época. Se refiere a una de las doce eras astrológicas, cuando el sol está en la constelación de Acuario durante la primavera. La era de Acuario es paz, amor, armonía y revelación. Los jóvenes se dejan crecer el pelo y protestan contra el establishment representado por el gobierno de los Estados Unidos (Wimmer 2008). Musicalmente, la canción es ecléctica y muy relajada gracias a instrumentos como el sitar, las campanillas, las guitarras eléctricas, las trompetas y el gong. Líricamente está relacionada con la paz, el amor y las estrellas: “Cuando la luna está en la séptima casa. Y Júpiter se alinea con Marte. Entonces la paz guiará los planetas. Y el amor dirigirá las estrellas. Este es el amanecer de la era de Acuario. La era de Acuario. ¡Acuario! ¡Acuario!”. xlii Pero además de la explicación astrológica, la canción también exalta las virtudes propias de los hippies: "Armonía y entendimiento, simpatía y abundante confianza, no más mentiras o burlas, dorados sueños vivos de Visiones, revelación mística cristalina y verdadera liberación de la mente... ¡Acuario!”. xliii

También a fines de los sesenta, el 18 de agosto de 1969 en Woodstock, se produce tal vez la mayor expresión musical contracultural cuando Jimi Hendrix interpreta en su guitarra el himno nacional de los Estados Unidos. Por esta insolencia Hendrix ha sido criticado y calificado como profanador y anti patria, pero también ha sido alabado por transformar a Star Spangled Banner ${ }^{x l i v}$ en una canción relevante y apreciable para una joven audiencia sesentera. En todo caso, esta ya mítica interpretación de Hendrix es entendida como una originalísima protesta contra la guerra de Vietnam.

Pero el himno de la contracultura por excelencia es "Imagine", la utopía de Lennon y de muchísima gente de entonces y de siempre. Una declaración cantada que 
hace imaginar un mejor mundo para todos. Musicalmente, es una melodía simple en la que Lennon canta acompañado de un acorde básico de piano y de una escueta percusión.

Imagina que no hay Paraíso. Es fácil si lo intentas. Ningún infierno debajo. Arriba solamente cielo. Imagina a todos viviendo para el presente. Imagina que no hay países. No es difícil pensarlo. No hay motivos para matar ni para morir. Tampoco hay religión. Imagina a toda la gente viviendo en paz. Imagina que no hay posesiones. Me pregunto si puedes. No hay necesidad de codicia ni de hambre. Una fraternidad de todos los hombres. Imagina a toda la gente compartiendo el mundo. Tú dirás que soy un soñador. Pero no soy el único. Espero que algún día te nos unas. Y el mundo será uno solo.

\section{Conclusiones}

La música y la cultura africanas tenían que surgir de alguna manera, las expresiones simbólicas habían estado reprimidas durante siglos y buscaban alguna ventana de escape para mostrarse. La generación beat había asumido algunas facetas de la cultura afroamericana: el jazz y algunas de sus costumbres subterráneas. El "mal comportamiento" en las vidas y en los textos de los poetas y escritores beat se plasmó en las letras de las canciones del naciente rock and roll, tal como se pudo evidenciar en el análisis textual. Los sentimientos típicos de los beat de extravío y pérdida, de deseo no concretado, de aspiración a un cambio de la sociedad, de separación de las personas amadas, de profundo dolor y nostalgia y de inspiración, natural y provocada, se transfirieron a la "poética" contenida en las lyrics de las canciones del rock and roll.

La rebeldía beat tomó la forma de un verdadero puente simbólico desde las expresiones culturales de la cultura africana "importada" a América. Este grupo de escritores antisistema logró contagiar su rebeldía a los nuevos juglares populares, un grupo emergente con una insurrecta propuesta contra un sistema cultural demasiado tradicional y rígido, una propuesta que "gestionaba" la mayoría de edad a una juventud no tomada en cuenta.

Estos jóvenes que debutaban en una sociedad de consumo querían también ser parte de la cultura y de la política. No querían solamente unirse a una sociedad de consumidores sino también querían proponer soluciones a una sociedad extremadamente tradicional y desigual en lo social y económico, mostrarse como un grupo capaz de asumir muchas cosas que no estaban previstas para ellos y dejar de ser excluidos social y políticamente.

El rock and roll, entonces, emergía como la expresión simbólica de los excluidos: los pobres, los negros, los jóvenes, los poetas underground y muchos otros que no tenían una forma de expresarse. Toda la amargura afroamericana, por siglos de opresión y exclusión, pudo ser interiorizada por una juventud excluida gracias a la intermediación de un grupo de insurrectos poetas que supieron dar valor a ciertas expresiones culturales y simbólicas de un grupo de migrantes a la fuerza, históricamente vulnerables y excluidos. La cultura africana cruzó el puente beat y contagió a los jóvenes creadores del rock and roll. 
El naciente rock and roll se instalaba como la voz de protesta de los jóvenes, una expresión que contenía toda la opresión de siglos de los afroamericanos y la rebeldía de la generación beat. La amargura afroamericana y la rebeldía poética se incorporaron en una expresión cultural y simbólica que en las siguientes décadas fue mutando y adquiriendo más y más expresiones de protesta en todo el mundo.

\section{Bibliografía}

Altschuler, Glenn C. 2003. All Shook Up. How Rock'n'Roll changed America. New York: Oxford University Press.

Berendt, Joachim E. 1994. El Jazz. De Nueva Orleáns al Jazz Rock. México D.F.: Fondo de Cultura Económica, primera reimpresión en español (FCE Colombia) de la primera edición en español (FCE México).

Blake, W. 1906. The Marriage of Heaven and Hell, John W. Luce and Company, Boston Inc., New York, 486 p.

Bogdanov, V. Woodstra, C. \& Erlewine S. T. (2002). All Music Guide to rock. The Definitive Guide to Rock, Pop, and Soul, 3rd edition. San Francisco: All Media Guide - Backbeat Books.

Burroughs, W. S. (2013). Yonqui, El almuerzo desnudo y Queer. Barcerlona: Anagrama, Colección Compendium.

Cook, B. (2011). La generación beat. Crónica del movimiento que agitó la cultura y el arte contemporáneo. Barcelona: Editorial Planeta S.A. Título original The Beat Generation. The Tumultuous '50s Movement and Its Impact on Today, Scribner, New York, 1971.

Copetas, C. (1974). "El padrino beat y el ídolo del glitter: Conversación entre David Bowie y William Burroughs", revista Rolling Stone.

Curtin, P. D. (1969). The Atlantic Slave Trade: a Census. Madison, Wisconsin: University of Wisconsin Press.

De Quincey, T. (1994). Del asesinato considerado como una de las Bellas Artes. Madrid: El Libro de Bolsillo, Alianza Editorial.

Dickinson, E. (2013). El viento comenzó a mecer la hierba. Editorial Nørdicalibros, Madrid, edición bilingüe, 180 páginas.

Garofalo, R. (1999). "From Music Publishing to MP3: Music and Industry in the Twentieth Century". American Music, 17 (3): 318-354, Autumn. Chicago: University of Illinois Press.

Gilchrist, A. (1998). The life of William Blake. New York: Dover Publications Inc., Mineola, originally published by John Lane, London (1907). 
Gilder Lehrman Institute of American History. 2014. "Creole World". En The Historic New Orleans Collection. New Orleans.

Ginsberg, A. (1993). Aullido y otros poemas. Madrid: Visor Libros.

Gioia, T. (2002). La Historia del Jazz. Madrid: Turner Publicaciones S.L.

Gioia, T. (2010). Blues. La música del Delta del Mississippi. Madrid: Turner Publicaciones S.L.

Götling, J. (2000). “Ley seca: trece años de violencia, locura y jazz”, artículo de opinión publicado en Diario Clarín, Edición del domingo 16 de enero. Buenos Aires.

Gysin, B. (2001). “Cut-Ups: A Project for Disastrous Success". En Back in no time: the Brion Gysin reader, editado por Jason Weiss. Middletown, CT: Wesleyan University Press.

Hall, S. (2007). "The Hippies: An American Moment", editado por Ann Gray, CCCS Selected Working Papers (December 20). Routledge.

Heatley, M. (2008). The Definitive Illustrated Encyclopedia of Rock. London: Flame Tree Publishing.

Henard, D. H. \& Rossetti, C. (2014). "All You Need is Love? Communication Insights from Pop Music's Number-One Hits”. Journal of Advertising Research: 13-26, March. Cambridge.

Hobsbawm, E. (2013) [1999]. Gente poco corriente. Resistencia, Rebelión y Jazz, Barcelona: Editorial Planeta S.A.

Huddleston, D. M. (2012). “The Beat Generation: They Were Hipsters Not Beatniks". Department of History seminar paper, Western Oregon University.

Jameson, F. (1991). "El posmodernismo como lógica cultural del capitalismo tardío". En Ensayos sobre posmodernismo. Buenos Aires: Ediciones Imago Mundi.

Jurado Morales, J. (2012). Las razones éticas del realismo. Revista Española (1953-1954) en la literatura del medio siglo. Sevilla: Colección Iluminaciones (Filología, crítica y ensayo), Editorial Renacimiento.

Kerouac, J. (1981). En el camino. Barcelona: Editorial Bruguera S.A.

Komara, E. (2006). Encyclopedia of the Blues. New York: Routledge, Taylor \& Francis Group.

Latham, A. (1976). "The Columbia murder that gave birth to the Beats". New York Magazine, 9(16): 41-53, April 19. New York.

Loliyong, T. (1991). "Problemas y temas en el estudio de la religión tradicional africana: Una presentación crítica de Westafrican Traditional Religion de Kofi Asare 
Opoku", artículo presentado en la sexta sesión del Congreso Internacional de Estudios Africanos en Khartun (Sudán) entre el 3 y el 10 de diciembre de 1991, pp. 497-514.

Lomax, A. (2002) [1941]. The Land where the Blues Began. New York: The New Press.

López Poy, M. (2009). Camino a la libertad. Historia social del blues. Barcelona: Editorial Bad Music Blues.

Lunch, L. (1998). "Herbert Huncke: Culpable de todo". En Flores del Fango, floresdelfango.blogspot.com, consultado el 23 de enero de 2015.

Parini, J. ed. \& Brett C. Millier. associate ed. (1993). The Columbia History of American Poetry. From the Puritans to Our Time. New York: MJF Books, Columbia University Press.

Rebollo, M. (2012). "5 postales de la generación Beat”. Revista Rolling Stone España: 38-40, 27 de diciembre Madrid.

Rolling Stone Magazine, autor. (1992) [1976]. The Rolling Stone Illustrated History of Rock and Roll: The Definitive History of the Most Important Artists and Their Music. New York: Random House.

Scaruffi, P. (2007). Una historia de la música rock, en www.scaruffi.com.

Sierra i Fabra, J. (2003). La era Rock (1953-2003). Madrid: Espasa Calpe S.A.

Springhall, J. (2008). The Genesis of Mass Culture. Show Business Live in America, 1840 to 1940. New York: Palgrave MacMillan.

Suiter, J. (2008). "When the Beats Came Back”. Reed Magazine, 87(1): 20-25. San Jose, CA: San Jose State University.

Thomas, D. (1981). Poemas completos. Buenos Aires: Ediciones Corregidor.

Whitburn, J. (2010). The Billboard Book of Top 40 Hits, revised and expanded ninth edition. New York: Billboard Books.

Whitman, W. (2007) Leaves of Grass, editado por Jim Manis, The Electronic Classic Series. Hazleton, PA: Pennsylvania State University. 


\section{Notas}

${ }^{i}$ Este artículo está basado en mi tesis doctoral Ruido, relato y mercancía. Economía política del rock, con la que obtuve el título de Doctor en Economía del Desarrollo en FLACSO, Ecuador (noviembre, 2017).

ii Anáfora es una palabra que viene del latín anaphora y del griego anáfora, y que significa repetición. Se refiere justamente a la repetición de una palabra dos o más veces o a la repetición de cualquier elemento de la oración utilizado pronombres indicativos para referirse a algo ya mencionado.

iii Son las auténticas raíces culturales-musicales de los blues. La Work Song (canción de trabajo) es un canto que acompaña al trabajo para que la larga jornada laboral sea lo más agradable posible, por lo general es cantado por varias personas. El Field Holler (grito de campo) es un canto con ritmo libre y sin acompañamiento, cantado por un trabajador en solitario (Lomax, A. 2002, 259, 273, 275, 353, 454). Los Spirituals (espirituales) son canciones afronorteamericanas, monofónicas y a capela, con texto religioso, por lo general son adaptaciones de la religiosidad africana en un contexto cristiano occidental.

iv Yehudi Menuhin (1916-1999), violinista y director de orquesta estadounidense de origen ruso y ascendencia judía, con nacionalidades suiza y británica. Es uno de los más grandes violinistas del siglo veinte, además de ser un activo defensor de causas humanitarias.

v Traducción mía de "The Africans are right, music is magic; it puts us in touch with the spirits of the past, and also of the future" (Menuhin y Davis 1979, 109).

vi Zip Coon es tal vez la más degradante y deshumanizante representación racista. Es una abreviatura de mapache (raccoon) y compara al negro con este perezoso y asustadizo animal. Jim Crow también es una representación deshumanizante en alusión al color negro del cuervo. La tradición de Jim Crow comenzó en entre los años 30 y 40 cuando los Virginia Minstrels se pintaban la cara con corcho quemado y hacían un show de canto y baile en un pequeño salón en New York. Su actuación fue tan exitosa que salieron de gira por otras ciudades y después varios otros juglares blancos los imitaron. Fue tan impactante el tema que después de la emancipación, entre 1860 y 1880, en la mayoría de los estados se promulgaron leyes segregacionistas para "regular" las relaciones sociales, económicas y políticas entre blancos y negros. Estas normas son conocidas como Jim Crow Laws (Toll 1974, 25-34).

vii “La rebelión de los esclavos de Haití, que se inició en 1791, estimulada y precedida por dos años de intensas luchas entre colonos franceses, y que enseguida se propagó con destrucción de haciendas y de vidas (...) Alimentada por la guerra internacional que pronto se inició y avivada por las tácticas de las diversas facciones francesas - de la isla y de la metrópoli-, terminó recién en 1804, cuando se declaró la independencia del nuevo país, con la economía colonial del azúcar en ruinas, y habiendo superado un episodio de reconquista intentado por Napoleón entre 1802 y 1803” (Di Tella 1984, 7).

viii Ver apartados "La geografía económica del blues: del delta del Níger al delta del Mississippi” y "Luisiana: a cultural crossroads y l'énigme du tambour africain" del segundo capítulo de la presente tesis.

ix "En la gélida medianoche del 17 de enero de 1920, uno de los más arraigados hábitos de la sociedad norteamericana hizo un cortocircuito: la Enmienda 18 entró en vigencia y legalmente se puso fin a la importación, exportación, fraccionamiento, transporte, venta o elaboración de toda bebida alcohólica. La denominada Ley de Prohibición Nacional, que se conoció en la jerga popular como Prohibición o Ley Volstead (por el diputado abstencionista de Minnessota Andrew Volstead, su principal promotor) ya había sido aprobada el año anterior, a pesar del veto del presidente Woodrow Wilson” (Göttling 2000).

x Ernst Wilhelm Julius Bornemann (1915-1995), antropólogo social, arqueólogo, psicoanalista, sexólogo, guionista de cine, compositor, etnomusicólogo y crítico de jazz. Privado de su nacionalidad alemana por negarse a cumplir con el servicio militar para el ejército hitleriano, decidió nacionalizarse austriaco.

xi Traducción mía de "Poets to come" (Poetas del futuro) de Walt Whitman: "Poets to come! Orators, singers, musicians to come! Not to-day is to justify me and answer what I am for. But you, a new brood, native, athletic, continental, greater than before known. Arouse! For you must justify me. I myself but write one or two indicative words for the future, I but advance a moment only to wheel and hurry back in the darkness. I am a man who, sauntering along without fully stopping, turns a casual look upon you and then averts his face, Leaving it to you to prove and define it, expecting the main things from you" (Whitman 2007, 37). 
xii Según el Diccionario de la Real Academia Española, láudano (del latín ladănum) es un extracto de opio, producido mediante la preparación compuesta de vino blanco, opio, azafrán y otras sustancias. Se trata de una sustancia estupefaciente.

xiii En 1838 Emerson dio un discurso conocido como "The Divinity School Address", que es una ruptura en la historia del unitarismo estadounidense. Influenciado por el hinduismo y el romanticismo alemán, propuso una vía alternativa para llegar a Dios, basada en la conciencia individual sin necesidad de mediaciones ni jerarquías religiosas: intuición, contemplación y éxtasis. Sin embargo, los "unitaristas" conservadores rechazaron las ideas de Emerson por considerarlas alejadas a una doctrina divina. Esta filosofía espiritual recibió el nombre de trascendentalismo.

xiv Poetisa y editora estadounidense (1860-1936), más conocida por su trabajo como fundadora y editora en jefe de The Poetry, revista dedicada exclusivamente a la poesía que dio forma al movimiento modernista en los Estados Unidos. Traducción mía de "American poet and editor Harriet Monroe (1860-1936) is best known for her work as founder and chief editor of Poetry, A Magazine of Verse, a periodical devoted solely to poetry that shaped the Modernist movement in the United States"' (MSS 099, F159, 'Harriet Monroe letters to Grant Hyde Code', Special Collections, University of Delaware Library, Newark, Delaware).

xv Traducción mía de "If the doors of perception were cleansed everything would appear to man as it is: infinite. For man has closed himself up, till he sees all things through narrow chinks of his cavern".

xvi Nacido en Minnesota en 1941 con el nombre de Robert Allen Zimmerman, autobautizado como Bob Dylan como muestra de adhesión al poeta galés.

xvii Traducción mía de "The Beat poet of Belmont Avenue (Leonard Cohen) said: 'Dylan Thomas was the great voice of poetry when I was at college. We (all the young poets) were all intrigued with his fame, his genius, his drinking, and his unconditional sense of social irresponsibility", mencionado en "The Two Dylans: Dylan Thomas, Bob Dylan and the Beat Generation", audiovisual, lecturas y discusión con la participación de los panelistas David Boucher (autor de Dylan and Cohen: Poets of Rock and Roll, The Political Art of Bob Dylan y varios artículos sobre Dylan Thomas, Bob Dylan y los Beats), Mike Jones (músico y autor de The Music Industries) y Jeff Towns (propietario de "Dylan's Bookshop" y coleccionista famoso de objetos relacionados con Dylan Thomas), realizado en el Aberystwyth Arts Centre, Aberystwyth, Gales, en marzo 18 de 2014.

xviii Dicho en Barcelona en diciembre de 1993 en una rueda de prensa (recogido por diario El País, 8 de diciembre de 1993, Barcelona).

xix Herbert Huncke (1915-1996) o "el rufián que inspiró a la generación Beat". Criado en Chicago. Desde adolescente fue vagabundo, ladrón y drogadicto. Se mudó a New York en 1939 donde conoció a Burroughs, Kerouac y Ginsberg, quienes lo incluyeron como personaje en sus libros: "Herman" en Junkie de Burroughs, "Elmer Hassel" en On the Road de Kerouac, "Huck" en Visions of Cody de Kerouac e incluso en Howl de Ginsberg sirvió como referente.

${ }^{x x}$ Del inglés junkie. En el lenguaje de la droga, término que se aplica a un adicto o toxicómano que consume drogas duras, en especial heroína (Ayto 1998, 162).

${ }^{x x i}$ Lydia Koch, conocida como Lydia Lunch, es una cantante neoyorquina, actriz, poetisa, fotógrafa, guionista de cine y escritora. Ha colaborado con varios artistas, entre ellos Nick Cave. Tiene un estilo musical muy variado con influencia de jazz, post-punk, noise, cabaret, soul y electrónica.

xxii Traducción mía de "The origins of the word 'beat' are obscure, but the meaning is only too clear to most Americans. More than mere weariness, [beat] implies the feeling of having been used, of being raw. It involves a sort of nakedness of mind, and, ultimately, of soul; a feeling of being reduced to the bedrock of consciousness. In short, [beat] means being undramatically pushed up against the wall of oneself [...]" (New York Times Magazine, November 16, 1952).

xxiii De acuerdo a The Oxford Dictionary of Slang, egghead o cabeza de huevo es un término creado en 1907 en los Estados Unidos y se aplica para referirse de manera despectiva a un intelectual porque se entiende que es una persona distante de la gente común y carente de realismo, a causa de sus intereses intelectuales.

xxiv Según The Oxford Dictionary of Slang, hispster es un término netamente estadounidense. En 1938 se escribía hepster y desde 1941 hipster. Se utiliza para definir a una persona entusiasta del jazz, del swing y de músicas de ese estilo.

${ }^{x x v}$ Sam Phillips era un locutor de radio proveniente del estado de Alabama, que vio en Memphis a la ciudad clave para el desarrollo de la música popular. Phillips estaba convencido que Memphis tenía buenas vibraciones musicales por ser el paso obligado de los emigrantes negros hacia el norte. En 1950 
fundó allí los Sun Studios donde grabaron bluseros de renombre como Howlin' Wolf y B.B. King, además de rocanroleros del nivel de Roy Orbison, Jerry Lee Lewis y Johnny Cash (Sierra i Fabra 2003, 26).

xxvi Si bien Eric Hobsbawm (1917-2012) había nacido en Alejandría y vivido en Austria y Alemania, fue en Inglaterra donde -junto con los "marxistas británicos" - desarrolló su vocación de historiador especializado en la clase obrera. Además de haber sido uno de los historiadores más importantes del siglo veinte, Hobsbawn fue un melómano. Pero, además de su gran afición a la música, fue un enamorado del jazz, tanto que realizó serias reflexiones sobre los procesos sociales relacionados con esta música.

xxvii O fox-trot, que en español significa literalmente "trote del zorro". Es un baile de salón asociado a las primeras orquestas de jazz y aparece en los Estados Unidos alrededor de 1912. Su nombre se origina en danzas tradicionales de tribus negras al imitar los movimientos de animales.

xxviii El kazzo, en español es conocido como mirlitón, consiste en un silbato o pito formado por una caña hueca y cerrada al menos en uno de sus extremos, con una membrana de papel o de algún material similar. $\mathrm{Al}$ soplar por una abertura en el centro, vibra produciendo un sonido nasal.

xxix La música de los afronorteamericanos de la primera mitad del siglo veinte, principalmente el Blues y el Jazz, solía ser rechazada por la sociedad blanca, al punto que era denominada "música de negros" o "música del diablo". Estas músicas negras son las antecesoras del rock británico (Domenech 2012, 13).

${ }^{x x x} \mathrm{O}$ McKinley Morganfield, que era su verdadero nombre, pero de niño solía revolcarse en los charcos de lodo y su abuela -quien lo crió- lo apodó Muddy Waters (Aguas Turbias).

xxxi Traducción de partes de "Working Class Hero" (1970) de John Lennon.

xxxii Don't Look Back (1967), dirigida por D.A. Pennebaker, con música de Bob Dylan y un reparto que incluye, además del propio Dylan, a Joan Baez, Donovan, Alan Price (ex Animals), Marianne Faithfull, John Mayall. Incluso Allen Ginsberg hace un cameo. Es un documental que cubre la gira británica de Bob Dylan en la primavera de 1965, cuando tenía 23 años. La gira de tres semanas es documentada por una cámara que le sigue donde va: aeropuerto, hotel y conciertos (filmaffinity.com).

xxxiii Renaldo and Clara (1978), dirigida por Bob Dylan, música de Bob Dylan y un reparto con Dylan, su primera esposa Sara, Ronnie Hawkins, Joan Baez, Joni Mitchell, Roberta Flack, Rubin "Hurricane" Carter y Allen Ginsberg. Es una película-documental-concierto, experimental y surrealista (Dylan interpreta a Renaldo mientras que Ronnie Hawkins interpreta a...Bob Dylan). Filmada durante la gira "Rolling Thunder Revue" entre 1975 y 1976. En la gira se juntaron figuras de la contracultura de la época (filmaffinity.com).

xxxiv El método de cut-up (o técnica de recortes) fue ideado en 1959 por el periodista y pintor Brion Gysin con base en los recortes en la pintura, y sistemáticamente aplicado por Burroughs en su obra literaria. Esta técnica se utiliza para lo que Gysin denominó "poemas de permutación": una frase se repite varias veces pero con las palabras reagrupadas en distinto orden en cada iteración (Gysin 2001, 125-132).

xxxv I heard Leadbelly and Blind Lemon / On the street where I was born, Sonny Terry, Brownie McGhee / Muddy Waters singin' "I'm a Rolling Stone" / I went home and read my Christmas Humphreys' book on Zen / Curiosity killed the cat / Kerouac's "Dharma Bums" and "On the Road".

xxxvi Traducción mía de "How many roads must a man walk down before you call him a man? (...) Yes, 'n' how many times must the cannonballs fly before they're forever banned? (...) Yes, 'n' how many deaths will it take till he knows that too many people have died? (...) The answer, my friend, is blowin' in the wind, the answer is blowin' in the wind" (Bob Dylan 1962).

xxxvii Traducción mía de "Come writers and critics who prophesize with your pen (...) the chance won’t come again (...) Come senators, congressmen, please heed the call, don't stand in the doorway (...) Come mothers and fathers throughout the land and don't criticize what you can't understand, your sons and your daughters are beyond your command, your old road is rapidly agin'. Please get out of the new one if you can't lend your hand, for the times they are a-changin"' (Bob Dylan 1964).

xxxviii CBC Digital Archives, consultado el 26 de abril de 2016.

xxxix Traducción de "Love, Love, Love (...) There's nothing you can do that can't be done / Nothing you can sing that can't be sung / Nothing you can say but you can learn how to play the game / It's Easy / There's nothing you can make that can't be made / No one you can save that can't be saved / Nothing you can do but you can learn to be you in time / It's Easy / All you need is love..." 
xl Según Vanesa Cordantonopulos (2002), el compás se usa para organizar el ritmo de la música distribuyendo el acento cada dos, tres o cuatro pulsos, pero haciendo énfasis en uno de ellos, de manera que el oído pueda percibirlos. De acuerdo al número de pulsos, los compases pueden ser binarios (2/4 dos negras, una por tiempo), ternarios ( $3 / 4$ tres negras, una por tiempo) y cuaternarios ( $4 / 4$ cuatro negras, una por tiempo). Estos últimos son compases simples. También hay compases compuestos y son binarios (6/8 dos negras con puntillo, una por tiempo), ternarios ( $9 / 8$ tres negras con puntillo, una por tiempo) y cuaternarios (12/8 cuatro negras con puntillo, una por tiempo). Pero existen también formas adicionales a manera de "amalgamas" de compases. La suma de $3 / 4$ y $4 / 4$ (o 4/4 y 3/4) da un compás de 7/4, utilizado desde que Stravinski compuso "La consagración de la Primavera". En el rock también hay casos como "All you need is love" y "Happiness is a warm gun" de los Beatles, "Money" de Pink Floyd, "Blackened" de Metallica y "Solsbury Hill" de Peter Gabriel, entre otros.

xli Hair. The American Tribal Love-Rock Musical (1966-69). Letras de Gerome Ragni y James Rado, música de Galt MacDermot. Es una ópera beat sobre la cultura hippie de los sesenta en los Estados Unidos, que hace énfasis en el amor, la paz, la libertad sexual y las drogas.

xlii Traducción de "When the moon is in the Seventh House. And Jupiter aligns with Mars. Then peace will guide the planets. And love will steer the stars. This is the dawning of the age of Aquarius. The age of Aquarius. Aquarius! Aquarius!” (The 5th Dimension 1968).

xliii Traducción de "Harmony and understanding, sympathy and trust abounding, no more falsehoods or derisions, golden living dreams of Visions, mystic crystal revelation, and the mind's true liberation... Aquarius!" (The 5th Dimension 1968).

xliv Nombre original de la canción patriótica, cuya letra fue escrita por Francis Scott Key el 14 de septiembre de 1814, durante la guerra de 1812 con Gran Bretaña. Fue aprobada por el Congreso como Himno Nacional de los Estados Unidos en 1931. 